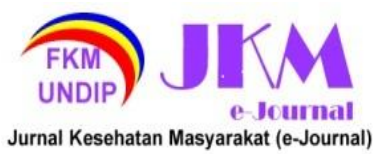

JURNAL KESEHATAN MASYARAKAT (e-Journal)

Volume 10, Nomor 1, Januari 2022

ISSN: 2715-5617 / e-ISSN: 2356-3346

http://ejournal3.undip.ac.id/index.php/jkm

\title{
ANALISIS KEBUTUHAN DAN PENGEMBANGAN TENAGA DOKTER UMUM DI PUSKESMAS NGALIYAN KOTA SEMARANG
}

\author{
Nurul Maulidiyah ${ }^{1 *}$, Intan Zainafree ${ }^{1}$ \\ ${ }^{1}$ Ilmu Kesehatan Masyarakat Fakultas Ilmu Keolahragaan Universitas Negeri Semarang \\ *Corresponding author: nurulmaulidiyah1003@gmail.com
}

\begin{abstract}
Ngaliyan Public Health Center has a high number of visitos which increases every year, but inversely proportional of the number of doctors, amounting to 3 people with 1 doctor concurrently serving as the head of the Public Health Center. This causes doctors to have a high workload which has an impact on non-optimal work result. The purpose of the study is to determine the optimal number of needs and development of doctors at the Ngaliyan Public Health Center. The type of research is descriptive qualitative using quantitative data with the WISN and Miles Huberman method. Data collection method using in-depth interviews. The result of the stude show that the availabele working time for doctors is 293,625 day/year and the standart alloweance is 0,009 per year. Based on the result of WISN ratio, the optimal number of doctors at the Public Health Center is 4 Doctors the result of the analysis development of doctor require further education, emergency training, disease updates and management training. In addition, the need for regular horizontal mutations and promotions to support career path. Ngaliyan Public Health Center lacks 1 Doctor and doctors need development through education, training, transfers and promotions.
\end{abstract}

Keywords: Needs analysis, doctors, development, WISN

\section{PENDAHULUAN}

Puskesmas merupakan gatekeeper sistem pelayanan kesehatan dimana fasilitas kesehatan tingkat pertama yang berperan sebagai pemberi pelayanan kesehatan dasar berfungsi optimal sesuai standar kompetensinya dan memberikan pelayanan kesehatan yang sesuai standar pelayanan medik. Bentuk pelayanan yang dilakukan kepada masyarakat berupa pelayanan promotif, preventif, kuratif dan rehabilitatif selain itu puskesmas juga memiliki peran yang sangat penting dalam membentuk Sistem Kesehatan Nasional (SKN) di Indonesia. ${ }^{1}$

Tenaga kesehatan di Puskesmas merupakan ujung tombak dalam menyediakan dan menyelenggarakan pelayanan kesehatan di tingkat dasar kepada masyarakat. Untuk mencapai pelayanan kesehatan yang optimal kepada masyarakat, maka perlu didukung oleh tenaga kesehatan yang mencukupi baik dari segi kuantitas maupun kualitas.

Permasalahan sumber daya manusia kesehatan di Indoenesia salah satunya adalah belum terpenuhinya kebutuhan tenaga kesehatan. Dilihat dari segi jumlah, kualitas serta penyebaran tenaga kesehatan terus meningkat akan tetapi masih belum mampu untuk memenuhi kebutuhan pelayanan kesehatan di seluruh wilayah Indonesia. Upaya untuk mendukung pengembangan tenaga kesehatan masih terbatas serta keserasian antara kebutuhan dan ketersediaan berbagai jenis kesehatan pada umumnya masih kurang.

Laporan Kementerian Kesehatan Republik Indonesia Tahun 2019 menunjukkan bahwa keadaan pemetaan Sumber Daya Manusia
Kesehatan (SDMK) 2019 jumlah tenaga kesehatan untuk dokter umum berjumlah 67.147 dengan rasio 25 per 100.000 penduduk, sedangkan jumlah dokter umum yang didayagunakan di Puskesmas berjumlah 24.216 dokter. Target rasio tenaga dokter umum pada tahun 2019 adalah 45 per 100.000 penduduk, hal ini menandakan bahwa jumlah tenaga dokter umum di Indonesia belum memadai dan masih kekurangan tenaga dokter umum.

Profil Kesehatan Provinsi Jawa Tengah tahun 2019 menunjukkan bahwa tenaga dokter masih di bawah target Indonesia Sehat yaitu 45/100.000 penduduk, yaitu 67.147 dokter dengan rasio 17,4 per 100.000 penduduk, sedangkan jumlah dokter umum yang didayagunakan di Puskesmas berjumlah 2.017 dokter, terlihat masih banyaknya kekurangan tenaga dokter umum di Jawa Tengah . Kota Semarang tahun 2019 ketersediaan tenaga dokter baru mencapai 4,35 Per 100.000 penduduk, dokter umum yang didayagunakan di Puskesmas berjumlah 79 dokter.

Profil Puskesmas Ngaliyan tahun 2020 menunjukkan bahwa di Puskesmas Ngaliyan tersedia tenaga dokter umum sebanyak 4 orang akan tetapi 2 dokter diantaranya purna tugas pada akhir tahun 2020 sehingga saat ini hanya tersedia sebanyak 3 orang dengan rincian 2 dokter tenaga pelaksana dan 1 dokter sebagai kepala puskesmas. Jumlah kunjungan pasien di Puskesmas Ngaliyan mengalami penurunan dari tahun 2019 sampai tahun 2020 yaitu dari 50.019 kunjungan menjadi 47.293 kunjungan. Penurunan kunjungan ini merupakan dampak dari adanya pandemi Covid-19. 


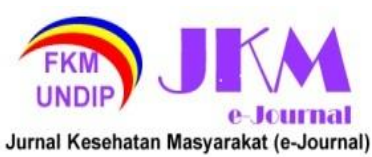

Meskipun mengalami penurunan, angka kunjungan di Puskesmas Ngaliyan masih tergolong tinggi.

Peraturan Menteri Kesehatan Nomor 75 Tahun 2014 tentang Puskesmas standar ketenagaan minimal di Puskesmas rawat inap untuk kategori dokter atau pemberi layanan primer berjumlah minimal 2. Secara jumlah Puskesmas Ngaliyan sudah sesuai dengan standar ketenagaan minimal akan tetapi beban kerja yang ditanggung termasuk tinggi, adanya pandemi secara tidak langsung menambah beban kerja dokter seperti pelayanan vaksin Covid-19. Jumlah kunjungan yang tinggi dan terbatasnya tenaga dokter mengakibatkan beban kerja yang tinggi yang akan berpengaruh terhadap produktivitas tenaga dokter itu sendiri.

Pernasalahan kekurangan tenaga harus dicermati dengan seksama, apakah memang benar memerlukan tambahan tenaga yang dikarenakan beban kerja berlebih sehingga akan mempengaruhi kualitas yang diberikan atau banyaknya waktu yang tidak produktif yang dilakukan oleh Sumber Daya Manusia (SDM) pada saat waktu bertugas. Kemerkes RI dan AIPHSS (Australia Indonesia Partnership for Health Systems Strengthening) telah menetapkan metode terbaru berdasarkan analisis beban kerja yaitu metode analisis beban kerja kesehatan (ABK kes) yang berpedoman pada Permenkes RI No.33 tahun 2015. Analisis beban kerja kesehatan (ABK kes) merupakan metode terbaru dari pengembangan aplikasi Rencana Kebutuhan SDM Kesehatan di Indonesia di dukung oleh Pemerintah Australia melalui program Penguatan Sistem Kesehatan.

Sehubungan hal tersebut dan mengingat pentingnya peningkatan profesionalisme tugas dan tanggung jawab serta pengembangan kualitas sumber daya manusia dalam rangka pencapaian tujuan pembangunan kesehatan maka peneliti tertarik untuk melakukan penelitian dengan judul "Analisis Kebutuhan dan Pengembangan Tenaga Dokter Umum di Puskesmas Ngaliyan Kota Semarang"

\section{METODE PENELITIAN}

Penelitian ini dilakukan di Puskesmas Ngaliyan Kota Semarang pada bulan juli sampai dengan bulan Agustus tahun 2021, objek dalam penelitian ini adalah beban kerja tenaga dokter umum di Puskesmas Ngaliyan Kota Semarang.

Jenis penelitian ini merupakan penelitian deskriptif kualitatif menggunakan data kuantitatif dengan metode WISN dan Miles Huberman. Sampel penelitian adalah seluruh tenagadokter umum sebanyak 3 orang yang bekerja di Puskesmas Ngaliyan. pengumpulan data primer dilakukan dengan Pengamatan langsung terhadap kegitaan yang dilakukan oleh dokter umum selama jam kerja, wawancara dengan beberapa informa dan data skeunder yang diperoleh dari data yang berasal dari bagian SDM Puskesmas, laporan dan laporan kinerja tenaga dokter umum.

Metode analisis yang digunakan dalam penelitian ini adalah dengan menggunakan metode Workload Indicator Staff Needs (WISN ) untuk mengetahui kebutuhan tenaga dokter umum dan metode Miles Huberman untuk mengetahui kebutuhan pengembangan tenaga dokter umum di Puskesmas Ngaliyan Kota Semarang.

\section{HASIL DAN PEMBAHASAN}

\section{Karakteristik Responden}

\begin{tabular}{lllllll}
\hline No & Kode informan & $\begin{array}{l}\text { Usia } \\
\text { (th) }\end{array}$ & $\begin{array}{l}\text { Masa } \\
\text { (tahun) }\end{array}$ & Kerja & Pendidikan & Jabatan \\
\hline 1 & Informan I & 34 & $>5$ & S1 & Dokter Fungsional \\
2 & Informan II & 38 & $>5$ & S1 & Dokter Fungsional \\
3 & Informan III & & $>5$ & S2 & Ka. Puskesmas \\
4 & Informan IV & 54 & $>5$ & S1 & Kepala TU Puskesmas \\
5 & Informan V & 50 & $>5$ & S2 & Kepala Seksi SDM Kesehatan \\
\hline
\end{tabular}

2. Kebutuhan Tenaga Dokter Umum dengan Metode WISN

a. Waktu Kerja Tersedia

\begin{tabular}{|c|c|c|c|}
\hline Kode & Faktor & $\begin{array}{ll}\text { Kategori } & \text { SDM } \\
\text { Dokter Umum } & \end{array}$ & Keterangan \\
\hline A & Hari kerja & 321 & Hari/tahun \\
\hline B & Cuti tahunan & 12 & Hari/tahun \\
\hline $\mathrm{C}$ & Pendidikan dan pelatihan & 0,375 & Hari/tahun \\
\hline $\mathrm{D}$ & Hari libur nasional & 15 & Hari/tahun \\
\hline $\mathrm{E}$ & Rata-rata ketidakhadiran kerja & 0 & Hari/tahun \\
\hline \multirow[t]{2}{*}{$\mathrm{F}$} & Waktu kerja & 5 & Jam/hari \\
\hline & Hari kerja tersedia & 293,625 & Hari/tahun \\
\hline
\end{tabular}




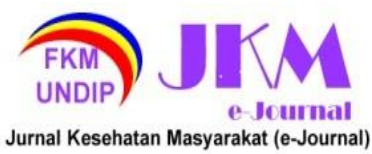

Waktu kerja tersedia
JURNAL KESEHATAN MASYARAKAT (e-Journal)

Volume 10, Nomor 1, Januari 2022

ISSN: 2715-5617 / e-ISSN: 2356-3346

http://ejournal3.undip.ac.id/index.php/jkm
$1.468,125$
Jam/tahun
$88.087,5$
Menit/tahun

b. Perhitungan Sandar Beban Kerja

\begin{tabular}{llll}
\hline No & Tugas Pokok Dokter Umum & $\begin{array}{l}\text { Rata-rata waktu } \\
\text { (menit) }\end{array}$ & Standar Beban Kerja \\
\hline 1 & Menguji kesehatan individu & 14 & 2936.25 \\
2 & Melakukan pelayanan medik umum & 26 & 3387.980769 \\
3 & Melakukan penyuluhan medik & 120 & 734.0625 \\
4 & Melakukan kunjungan pasien rawat inap & 15 & 2936.25 \\
5 & Melakukan tindakan khusus oleh dokter umum & 30 & 1468.125 \\
6 & Melayani/menerima konsultasi dari luar & 17 & 4404.375 \\
7 & Melayani/menerima konsultasi dari dalam & 17 & 2936.25 \\
8 & Membuat catatan medik rawat rawat inap & 15 & 2936.25 \\
9 & Membuat catatan medik rawat rawat jalan & 15 & 5872.5 \\
10 & Melakukan pemulihan fisik & 14 & 2936.25 \\
11 & Melakukan pemulihan mental & 16 & 2516.785714 \\
12 & Melakukan tindakan darurat medik/P3K & 26 & 2516.785714 \\
\hline
\end{tabular}

c. Penyusunan Standar Kelonggaran

\begin{tabular}{lccc}
\hline Faktor Kelonggaran & Rata-rata Waktu & Jumlah & $\begin{array}{l}\text { Standar } \\
\text { Kelonggaran }\end{array}$ \\
\hline $\begin{array}{l}\text { Standar Kelonggaran Kategori (terkait kegiatan produktif tidak langsung) } \\
\text { Rapat rutin bulanan }\end{array}$ & 2 jam/3 bulan & 8 jam/tahun & 0.004 \\
$\begin{array}{l}\text { Standar Kelonggaran Individu } \\
\text { Pendidikan dan pelatihan }\end{array}$ & 9 jam/tahun & 9 jam/tahun & 0.005 \\
Jumlah & & & 0.009 \\
\hline
\end{tabular}

d. Kuantitas Kegiatan Pokok

\begin{tabular}{lll}
\hline No & Tugas Pokok Dokter Umum & $\begin{array}{l}\text { Kuantitas } \\
\text { (1 Tahun) }\end{array}$ \\
\hline 1 & Menguji kesehatan individu & 390 \\
2 & Melakukan pelayanan medik umum & 6020 \\
3 & Melakukan penyuluhan medik & 16 \\
4 & Melakukan kunjungan pasien rawat inap & 15 \\
5 & Melakukan tindakan khusus oleh dokter umum & 348 \\
6 & Melayani/menerima konsultasi dari luar & 780 \\
7 & Melayani/menerima konsultasi dari dalam & 450 \\
8 & Membuat catatan medik rawat rawat inap & 15 \\
9 & Membuat catatan medik rawat rawat jalan & 6020 \\
10 & Melakukan pemulihan fisik & 610 \\
11 & Melakukan pemulihan mental & 480 \\
12 & Melakukan tindakan darurat medik/P3K & 56 \\
13 & Menguji kesehatan individu & 80 \\
\hline
\end{tabular}

e. Perhitungan Kebutuhan Tenaga Dokter Umum

\begin{tabular}{lllll}
\hline No & Tugas Pokok Dokter Umum & $\begin{array}{l}\text { Standar } \\
\text { Kerja }\end{array}$ & $\begin{array}{l}\text { Beban } \\
\text { Kegiatan } \\
\text { pokok }\end{array}$ & $\begin{array}{l}\text { Kebutuhan } \\
\text { SDM }\end{array}$ \\
\hline 1 & Menguji kesehatan individu & 6291.964286 & 390 & 0.061983823 \\
2 & Melakukan pelayanan medik umum & 3387.980769 & 6020 & 1.77686959 \\
3 & Melakukan penyuluhan medik & 734.0625 & 16 & 0.021796509 \\
4 & Melakukan kunjungan pasien rawat inap & 5872.5 & 15 & 0.002554278 \\
5 & Melakukan tindakan khusus oleh dokter umum & 2936.25 & 348 & 0.118518519 \\
6 & Melayani/menerima konsultasi dari luar & 5181.617647 & 780 & 0.150532141 \\
7 & Melayani/menerima konsultasi dari dalam & 5181.617647 & 450 & 0.086845466 \\
8 & Membuat catatan medik rawat rawat inap & 5872.5 & 15 & 0.002554278
\end{tabular}




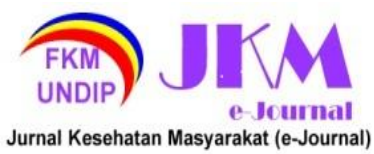

JURNAL KESEHATAN MASYARAKAT (e-Journal)

Volume 10, Nomor 1, Januari 2022

ISSN: 2715-5617 / e-ISSN: 2356-3346

http://ejournal3.undip.ac.id/index.php/jkm

\begin{tabular}{|c|c|c|c|c|}
\hline 9 & Membuat catatan medik rawat rawat jalan & 5872.5 & 6020 & 1.025117071 \\
\hline 10 & Melakukan pemulihan fisik & 6291.964286 & 610 & 0.096949056 \\
\hline 11 & Melakukan pemulihan mental & 5505.46875 & 480 & 0.087186037 \\
\hline 12 & Melakukan tindakan darurat medik/P3K & 3387.980769 & 56 & 0.016529019 \\
\hline 13 & Menguji kesehatan individu & 2446.875 & 80 & 0.032694764 \\
\hline \multicolumn{4}{|c|}{ Sub total kebutuhan SDM } & 3.480130552 \\
\hline \multicolumn{4}{|c|}{ Standar Kelonggaran } & 0,009 \\
\hline \multicolumn{4}{|c|}{ Jumlah kebutuhan SDM dengan menggunakan metode WISN } & 3.489130552 \\
\hline
\end{tabular}

f. WISN Rasio

\begin{tabular}{llllllll}
\hline No & Poli Umum & $\begin{array}{l}\text { Staf } \\
\text { ada } \\
\text { (a) }\end{array}$ & $\begin{array}{l}\text { yang } \\
\text { Dokter }\end{array}$ & $\begin{array}{l}\text { Kebutuhan } \\
\text { staf } \\
\text { (b) }\end{array}$ & $\begin{array}{l}\text { Kurang/lebih } \\
\text { (a-b) }\end{array}$ & $\begin{array}{l}\text { WISN } \\
\text { Ration } \\
(\mathbf{a} / \mathbf{b})\end{array}$ & $\begin{array}{l}\text { Keadaan } \\
\text { masalah } \\
\text { staf }\end{array}$ \\
\hline $\begin{array}{l}\text { Fungsional } \\
\text { Dmum }\end{array}$ & 3 & 4 & 1 & 0,75 & Kurang staf \\
\hline
\end{tabular}

\section{PEMBAHASAN}

Analisis Kebutuhan Tenaga Dokter Umum dengan Metode WISN

Dalam menghitung kebutuhan SDMK berdasarkan analisis beban kerja menurut metode Workload Indicator Staff Needs (WISN) beberapa faktor yang diperlukan antara lain:

a. Menetapkan Waktu Kerja Tersedia

Berdasarkan hasil penelitian hari kerja tersedia selama tahun 2020, sesuai dengan ketentuan yang berlaku di Kota Semarang termasuk di Puskesmas Ngaliyan yaitu 6 hari kerja, hari Senin sampai dengan hari Sabtu. Hari kerja menyesuaikan dengan kalender nasional yang ada, sedangkan hari libur mengikuti ketetapan seperti hari libur nasional dan cuti bersama. Menurut informan selama pandemic Covid-19 cuti bersama tidak dihihtung sebagai hari libur, sedangkan cuti tahunan tersedia 12 hari akan tetapi sampai saat ini belum dimanfaatkan.

Ketidakhadiran kerja, seperti yang sudah dijelaskan pada bagian hasil penelitian, pada prinsipnya ada kebijakan kepala puskesmas unrtuk ketidakhadiran kerja karyawan, seperti izin sakit, atau ada keperluan keluarga, dll. Akan tetapi belum ada ketentuan untuk jumlah hari yang disepakati untuk ketidakhadiran kerja tersebut. Hal ini tentu menjadi kebijakan yang perlu disikapi lebih lanjut, karena tidak adanya kebijakan tentang ketidakhadiran kerja akan sangat memengaruhi jumlah waktu kerja masing-masing SDMK di Puskesmas Ngaliyan.

Ketidakhadiran kerja akan berpengaruh terhada kauntitas dan kualitas dalam memberikan pelayanan kesehatan kepada masyarakat. Semakin banyak ketidakhadiran kerja, semakin sedikit jumlah hari dan waktu kerja tersedia, kualitas pelayanan kesehatan yang diberikan akan semakin berkurang karena beban kerja yang tinggi. Dari hasil wawancara yang dilakukan, hampir seluruh informan memberikan jawaban yang sama bahwa Puskesmas memberikan kesempatan izin yang tidak terbatas selama ada pemberitahuan dan pelayanan pasien tetap berjalan pada masa sebelum pandemic Covid-19, akan tetapi selama masa pandemi Covid-19 ketidakhadiran kerja hanya diberikan kepada petugas Puskesmas yang izin sakit.

Sebelum masa pandemi Covid-19 dokter umum mengikuti kegiatan pendidikan dan pelatihan minimal 1 (satu) kali dalam satu tahun selama 3 hari kerja. Sedangkan selama masa pandemi Covid-19, kesempatan dokter umum dalam mengikuti pendidikan dan pelatihan dibatasi, boleh mengikuti kegiatan pendidikan dan pelatihan akan tetapi tidak boleh mengganggu jam kerja dalam memberikan pelayanan di Puskesmas Ngaliyan.

Berdasarkan hasil wawancara, waktu kerja dokter umum di Puskesmas Ngaliyan selama masa pandemic yaitu 6 jam/hari sehingga waktu kerja tersedia dokter umum di Puskesmas Ngaliyan dalam kurun waktu satu tahun yaitu 293,625 hari atau 1.468,125 jam/tahun atau 88.087,5 menit/tahun

b. Standar Beban Kerja

Standar beban kerja berdasarkan Kepmenkes RI NO 81 Tahun 2004, adalah kuantitas/volume beban kerja selama 1 (satu) tahun per kategori SDM, yang disusun berdasarkan rata-rata waktu yang dibutuhkan untuk menyelesaikannya. Sedangkan kuantitas beban kerja merupakan setiap kegiatan pokok bagi dokter umum dan perawat di Poli Umum Puskesmas Ngaliyan.

c. Standar Kelonggaran

Standar Kelonggaran berdasarkan Kepmenkes RI No 81 Tahun 2004 adalah standar yang tercatat oleh manajmen yang rutin dan wajib dilakukan setiap tahun. Standar kelonggaran dibagi menjadi dua standar kelonggaran yaitu standar kelonggaran kategori yaitu standar kelonggaran yang terkait kegiatan produktif tidak langsung seperti rapat rutin bulanan dan standar kelonggaran 


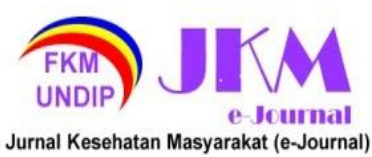

individu seperti waktu untuk mengikuti pendidikan dan pelatihan.

Dimasa pandemic Covid-19 dokter umum Puskesmas Ngaliyan lebih memfokuskan pada kegiatan pokok karena terbatasnya waktu kerja tersedia sehingga kegiatan tidak langsung seperti rapat rutin, pendidikan dan pelatihan dikurangi kuantitas waktunya. Berdasarkan perhitungan didapatkan standar kelonggaran dokter umum di Puskesmas Ngaliyan selama masa pandemi yaitu 0,009 .

d. Perhitungan Kebutuhan SDM

Menghitung jumlah kebutuhan SDM menggunakan metode WISN harus berdasarkan data dengan kuantitas kegiatan pokok selama satu tahun kemudian dibagi dengan standar beban kerja tiap kategori kegiatan pokok, kemudian ditambahkan faktor kelonggaran.

Hasil perhitungan kebutuhan tenaga dokter umum berdasarkan metode Workload Indicator Staff Need (WISN) menunjukkan bahwa jumlah kebutuhan tenaga dokter umum di Puskesmas Ngaliyan adalah sebanyak 3.49 ditambah dengan total standar kelonggaran 0.009 jadi jumlah dokter umum yang dibutuhkan adalah 3.5 dibulatkan menjadi 4 orang. Hal ini akan menyebabkan kinerja dokter yang kurang maksimal dan kurangnya tenaga dengan beban kerja tinggi dapat mengakibatkan stress kerja yang berpengaruh buruk bagi pelayanan Puskesmas.

Perhitungan ini memiliki rasio WISN adalah 0,75 berdasarkan rasio diatas jika rasio WISN $<1$ artinya SDM pada unit tersebut belum mencukupi dan belum sesuai dengan beban kerja. Jumlah dokter umum yang ada di Puskesmas Ngaliyan adalah 3 orang dengan 1 orang dokter merangkap sebagai Kepala Puskesmas sedangkan kebutuhan menurut WISN adalah 4 orang dokter umum.

Hasil perhitungan ini sejalan dengan jurnal penelitian yang berjudul Analisis Beban Kerja Dokter dan Perawat di Poli Umum Puskesmas Kedaton Kota Bandar Lampung dengan Metode WISN yang dilakukan oleh (2) yaitu memiliki rasio WISN 0,5 untuk tenaga dokter umum artinya jumlah tenaga dokter saat ini lebih kecil dibandingkan dengan jumlah tenaga yang dibutuhkan dan rasio WISN 1 untuk perawat. Kekurangan jumlah tenaga yang dibutuhkan mengakibatkan produktivitas menurun yang akan memacu stress kerja yang berdampak pada keselamatan pasien.

Pernyataan tersebut juga didukung jurnal yang berjudul Analisis Beban Kerja Dokter Umum di Puskesmas Kota Denpasar dengan Menggunakan Metode Workload Indicator of Staffing Need (3) hasil analisis menunjukkan bahwa beban kerja dokter umum di Puskesmas Kota Denpasar termasuk tinggi dengan rasio 0,5-0,9. Beban kerja yang dianggap sesuai adalah apabila rasio beban kerja sama dengan satu. Dari analisis dapat dilihat bahwa semua puskesmas di Kota Denpasar mengalami kekurangan dokter umum dengan jumlah kekurangan yang bervariasi.

Pernyataan tersebut didukung oleh jurnal penelitian yang berjudul Making the Transition to Workload Based Staffing: Using the Workload Indicators of Staffing Need method in Uganda oleh Namaganda, Oketcho, Maniple, \& Viadro (2015) Hasil penelitian dari analisa kebutuhan tenaga kesehatan (Keperawatan asisten, perawat, bidan, petugas klinis, dokter) dengan metode WISN, di fasilitas kesehatan terdapat tiga jenis Pusat Kesehatan yang memiliki kekurangan perawat (42$70 \%$ ) dan bidan $(53,67 \%)$ dari yang diperlukan dan mengakibatkan tekanan beban kerja yang tinggi (30-58\%). Pusat kesehatan IV dan Rumah Sakit memiliki kekurangan tenaga dokter $(39-42 \%)$ dan didapatkan hasil dari semua fasilitas didapatkan overstaffing dengan jenis staff asisten keperawatan. Hasil ini dapat dijadikan sebagai bukti dasar untuk pembentukan kembali kebijakan dan pengambilan keputusan, dengan mengadopsi norma-norma yang berbasis beban kerja, untuk meninjau kecukupan, kelebihan atau normal pada praktek kerja tengaa kesehatan di semua fasilitas kesehatan dan sebagai target investasi sumber daya manusia di masa depan.

Implikasi dari kekurangan tenaga kesehatan di Puskesmas adalah tingginya beban kerja tenaga kesehatan dan terhambatnya pelaksanaan program kesehatan. Tinggi rendahnya beban kerja dapat diukur berdasarkan perbandingan antara beban kerja yang ada terhadap standar beban kerja yang dihitung menggunakan rumus yang telah ditetapkan. Menurut Kusuma, Mahfudnurnajamuddin, \& Arfah (2021) beban kerja berpengaruh positif dan signifikan terhadap kinerja tenaga perawat di Unit Pelayanan Rawat Inap RSU Andi Makkassau Kota Parepare, artinya semakin meningkat upaya mengatasi beban kerja maka semain meningkat pula kinerja perawat. Beban kerja merupakan salah satu faktor penting setelah stress kerja dalam peningkatan kinerja tenaga kesehatan di Puskesmas.

Pernyataan diatas didukung oleh penelitian Maharani dengan judul Pengaruh Beban Kerja terhadap Stress Kerja dan Kinerja Perawat Rawat Inap Dalam hasil penelitian menunjukkan bahwa terdapat pengaruh langsung beban kerja terhadap beban kerja, beban kerja perawat rawat inap dalam di BLUD RSU Kota Banjar termasuk dalam kategori sangat tinggi. ${ }^{2}$ Pengaruh tidak langsung yaitu beban kerja ke kinerja lalu ke strees kerja, adapun kinerja perawat rawat inap dalam di BLUD RSU Kota Banjar termasuk kategori rendah, 


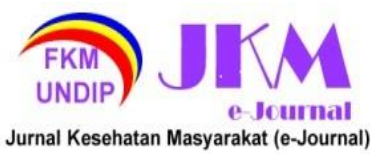

kemudian untuk stress kerja di BLUD RSU Kota Banjar termasuk tinggi.

Berdasarkan penelitian Maryati yang berjudul Dampak Beban Kerja Coder yang Tinggi terhadap Ketidakakuratan Kode Diagonosis hasil penelitian menunjukkan bahwa terdapat hubungan yang signifikan antara beban kerja coder dengan keakuratan diagnosis, artinya semakin tinggi beban kerja coder akan meningkatkan ketidakakuratan diagnosis. ${ }^{3}$

Analisis Pengembangan Tenaga Dokter Umum Pengembangan SDM sangat diperlukan untuk dilakukan secara terencana dan berkesinambungan. Pengembangan SDM menjadi sangat penting karena tuntutan jabatan dari suatu pekerjaan dipengaruhi oleh perkembangan Ilmu Pengetahuan dan Teknologi (IPTEK) serta semakin ketatnya persaingan.

\section{Pendidikan}

Pendidikan menurut Djalla merupakan suatu indikator yang mencerminkan kemampuan seseorang untuk dapat mengerjakan suatu pekerjaan. Karena dengan latar belakang pendidikan ini seseorang dianggap mampu menjabat sutau jabatan dimana tingkatan pendidikan diperoleh melalui pendidikan formal dan pendidikan tambahan (pelatihan yang pernah diikuti). ${ }^{4}$ Pendidikan dapat mempengaruhi profesionalismes petugas kesehatan di Puskesmas.

Dari hasil penelitian yang diperoleh dari penelitian yaitu Dokter Umum yang bertugas di Puskesmas Ngaliyan berlum pernah mendapatkan kesempatan untuk melanjutkan pendidikan ke tingkat yang lebih tinggi sebagai upaya pengembangan diri. Sesuai dengan pendapat Sulistiyani bahwa seseorang yang mengikuti pendidikan lanjut maka dia mempunyai kesempatan dan peluang untuk mencapai pengembangan diri yang lebih tinggi dalam mempersiapkan penngembangan karirnya.

Menurut Junaidi dalam jurnal yang berjudul Pengaruh Pendidikan dan Pelatihan terhadap Kinerja Pegawai di Puskesmas Besuk Kecamatan Besuk Kabupaten Probolinggo, hasil penelitian menunjukkan bahwa terdapat pengaruh yang signifikan secara parsial antara pendidikan dan pelatihan terhadap kinerja pegawai di Puskesmas Besuk Kabupaten Probolinggo. Dari hasil analisis terbukti bahwa variabel pendidikan yang berpengaruh dominan terhadap kinerja pegawai di Puskesmas Besuk Kabupaten Probolinggo. ${ }^{5}$

2. Pelatihan

Menurut (8) dalam jurnal yang berjudul Faktor-faktor yang Mempengaruhi Profesionalisme Petugas Kesehatan di Puskesmas Baroko Kabupaten Enerkang, pelatihan merupakan bagian dari investasi jangka panjang SDM untuk meningkatkan keampuan serta keterampilan kerja yang berpengaruh terhadap peningkatan kinerja pegawai. Pelatihan biasanya dilakukan dengan kurikulum yang sudah disesuaikan dengan kebutuhan jabatan, diberikan dalam waktuyang relative pendek untuk membekali SDM dengan keterampilan kerja. Pelatihan juga berpengaruh terhadap profeionalisme SDM kesehatan di Puskesmas.

Dari hasil penelitian, meski sudah memiliki pengalaman kerja $>5$ tahun dokter umum di Puskesmas Ngaliyan merasa sangat membutuhkan atau menginginkan adanya penyegaran ataupun peningkatan kemampuan melalui kegiatan pelatihan atau kursus. Pelatihan mempunyai andil besar dalam meningkatkan kecakapan dan kamampuan dokter agar lebih maksimal dalam memberikan pelayanan ke pasien, selain itu pelatihan mempunyai tujuan untuk meningkatkan efisiensi dan efektivitas kerja dokter dalam mencapai sasaran kerja yang telah ditetapkan.

Menurut Maisirata dalam jurnal yang berjudul Penilaian Efektivitas Pelatihan Bagi Peningkatan Prestasi Kerja Karyawan Swasta di Kota Pontianak, Pelatihan bagi peningkatan prestasi kerja karyawan berpengaruh terhadap semangat kerja, tingkat pengetahuan dan keterampilan, hubungan kerjasama antara pimpinan dengan bawahan, dan hubungan kerjasama antar karyawan yang semakin baik dan harmonis. ${ }^{6}$

3. Mutasi

Mutasi merupakan tindak lanjut dari hasil penilaian prestasi dari sebuah kinerja. mutasi bertujuan untuk melakukan penyegaran dalam rangka meningkatkan produktivitas SDM dalam mencapai kinerja yang lebih baik dan tepat sasaran. Hasil penelitian menunjukkan bahwa semua dokter umum di Puskesmas Ngaliyan sudah pernah mendapatkan kesempatan untuk mutasi horizontal dengan rentan waktu yang berbeda-beda.

Berdasarkan hasil wawancara menunjukkan bahwa pelaksanaan mutasi merupakan hak prerogratif dari atasan yaitu Dinas Kesehatan Kota sehingga tidak dapat dipastikan alasan dilakukannya mutasi tersebut. Salah satu alasan yang menjadi alasan dilakukannya mutasi adalah adanya kekurangan dokter di satu puskesmas. Menurut (11) ada beberapa alasan yang menjadi penyebab sesorang mutasi antara lain:

a. Keinginan seorang pegawai untuk mengikuti suami atau istrinya atau dengan kata lain mengikuti keluarganya sehingga dekat dengannya,

b. Pegawai ataupun karyawan dapat mengajukan mutasi hal ini didasari atas pertimbangan faktor usia yang sudah tua dan memiliki anak sehingga perlunya jangkauan dengan anakanaknya. 


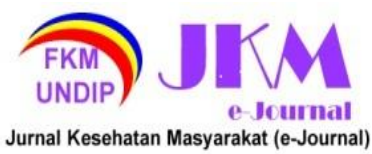

Berdasarkan wawancara tujuan dilakukan mutasi yaitu untuk sebagai media belajar untuk meningkatan pengetahuan serta pengalaman, menghindari kejenuhan dengan suasanan tempat kerja baru karena terlalu lama bekerja di satu tempat yang sama dan sebagai saran untuk pengembangan karir. Berdasarkan peraturan Badan Kepegawaian Negara Nomor 5 Tahun 2019 tujuan pelaksanaan mutasi sebagai berikut:

a. Penilaian kompetensi

b. Sector pemetaan pegawai

c. Kelompok perencanaan

d. Karir karyawan

e. Sumber daya pengembangan pegawai

f. Prestasi dan lowongan organisasi

g. Sifat teknis dan kriteria kebijakan

Hasil penelitian dengan judul Pengaruh Mutasi terhadap Semangat Kerja Pegawai Negeri Sipil pada Kantor Pelayanan Pajak Pratama Kota Pematang Siantar oleh Ambarita yaitu secara keseluruhan terdapat pengaruh positif antara mutasi kerja terhadap semangat kerja pegawai KPP Pratama Kota Pematang Siantar. ${ }^{7}$ Pernyataan ini didukung oleh penelitian Awisna dalam jurnal yang berjudul Pengaruh Mutasi terhadap Motivasi Kerja Pegawai pada Kantor Dinas Kesehatan Kabupaten Aceh Tamiang, menyatakan bahwa ada pengaruh antara mutasi dan motivasi kerja di Kantor Kantor Dinas Kesehatan Kabupaten Aceh Tamiang. Dengan kata lain jika mutasi dapat dilaksanakan dengan sebaik-baiknya maka akan berpengaruh terhadap motivasi kerja di Kantor Dinas Kesehatan Kabupaten Aceh Tamiang. ${ }^{8}$

4. Promosi

Promosi adalah perpindahan SDM dari jabatan satu ke jabatan yang lain pada jenjang eselon yang lebih tinggi karena pertimbangan jenjang karir. Menurut (14) promosi jabatan adalah kenaikan suatu jabatan pegawai dari jabatan lama ke jabatan yang baru dan lebih tinggi dengan syarat dan faktor tertentu. Promosi ini dijadikan sebagai bentuk promosi pemerintah kepada pegawai yang dimutasi.

Menurut (15) dalam jurnal berjudul Pengaruh Promosi Jabatan terhadap Kinerja Karyawan pada PT. Garuda Metalindo yaitu ada pengaruh promosi jabatan terhadap kinerja karyawan. Promosi jabatan PT. Garuda Metalindo bagian produksi dapat termotivasi untuk lebih baik dan lebih giat lagi bekerja agar mendapatkan penilaian yang baik, dengan harapan karyawan tersebut mendapatkan promosi jabatan.

Pernyataan tersebut di dukung oleh jurnal penelitian berjudul Hubungan Antara Kinerja Karyawan Dengan Promosi Jabatan Pada Unit Taman Marga Satwa Ragunan Dinas Kehutanan Provinsi DKI Jakarta oleh Syahyuni yang menyatakan bahwa ada hubungan yang sangat erat antara kinerja dan promosi jabatan. ${ }^{9}$ Kinerja memberikan pengaruh terhadap proses promosi jabatan dan pengaruhnya sangat besar.

Menurut Saharuddin dalam jurnal yang berjudul Pengaruh Kreativitas dan Promosi Jabatan terhadap Peningkatan Produktivitas, hasil penelitian menunjukkan bahwa promosi jabatan berpengaruh secara parsial signifikan terhadap produktivitas. Promosi dianggap lebih menarik dibandingkan dengan kompensasi lain hal ini disebabkan karena promosi bersifat permanen dan bertahan dalam jangka waktu lama. ${ }^{10}$

Menurut Siregar dalam jurnal berjudul Faktor Determinan Pengembangan Jenjang Karir Perawat Di RSUD Pasar Minggu Jakarta Selatan ada beberapa faktor penentu utama dalam pengembangan jenjang karir antara lain kebijakan dalam organisasi, prestasi kerja, mentor-sponsor, budaya organisasi, jejaring kerja, sistem penghargaan dan peluang untuk pertumbuhan karir. ${ }^{11}$

\section{KESIMPULAN}

Waktu kerja tersedia tenaga dokter umum di Puskesmas Ngaliyan Kota Semarang yaitu 293,625 hari atau 1.468,125 jam/tahun atau 88.087,5 menit/tahun. Standar kelonggaran tenaga dokter umum di Puskesmas Ngaliyan Kota Semarang yaitu 0,009 per tahun. Berdasarkan hasil analisis rasio WISN didapatkan jumlah perkiraan kebutuhan tenaga Dokter Umum di Puskesmas adalah 4 orang.

Kebutuhan pengembangan tenaga dokter umum melalui pelatihan di Puskesmas Ngaliyan Kota Semarang yaitu pendidikan lanjutan formal untuk meningkatkan keahlian dan kompetensi, pelatihan antara lain penelitian terkait dengan kegawatdaruratan, update (pembaharuan) penyakit, pelatihan yang berkaitan dengan manajemen puskesmas. Selain itu, dokter umum di Puskesmas Ngaliyan membutuhkan pengembangan dari segi mutasi yaitu mutasi secara horizontal yang dilakukan secara rutin dalam jangka waktu 4 sampai 5 tahun sekali, dan pengembangan dalam bentuk promosi yaitu keniakan jabatan 1 (satu) tingkat lebih tinggi dari jabatan sebelumnya guna mendukung jenjang karir.

\section{SARAN}

1. Bagi Puskesmas Ngaliyan

a. Untuk mengatasi waktu kerja yang masih kurang, hendaknya puskesmas menambahkan waktu kerja dengan memulai jam kerja lebih cepat dan mengakhirinya lebih lama.

b. Untuk mengatasi beban kerja yang berlebih, hendaknya Puskesmas Ngaliyan perlu menambahkan 1 orang dokter umum puskesmas yang memiliki kompetensi yang 


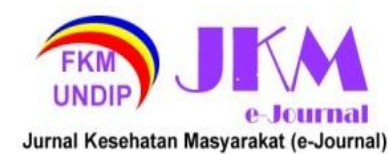

sesuai dengan kebutuhan Puskesmas sehingga pelayanan yang diberikan kepada masyarakat lebih optimal

c. Hendaknya Puskesmas melakukan survey kepada tenaga dokter umum untuk mengetahui jenis pengembangan yang dibutuhkan dilihat dari segi pendidikan, pelatihan dan mutasi.

2. Bagi Dinas Kesehatan Kota Semarang

a. Untuk menunjang pengembangan bagi tenaga kesehatan di Puskesmas, hendaknya Dinas Kesehatan Kota Semarang memberikan program pengembangan yang meliputi pendidikan, pelatihan, promosi dan mutasi sesuai dengan kebutuhan dokter umum

3. Bagi Peneliti Lain

a. Hendaknya melakukan penelitian dengan melakukan Pengamatan secara langsung kegiatan dokter umum dengan waktu yang lebih lama agar dapat mewakili keadaan sebenarnya dengan menggunakan metode yang lain seperti time motion study.

b. Peneliti menyarankan untuk dilakukan penelitian lebih lanjut secara kuantitatif untuk beban kerja tenaga kesehatan di seluruh unit kerja Puskesmas

\section{DAFTAR PUSTAKA}

1. Wulandari F. K, Achadi A. Analisis Karakteristik dan Persepsi Pengguna Pelayanan Terhadap Pemanfaatan Puskesmas Sebagai Gatekeeper di Dua Puskesmas Kota Bekasi Tahun 2016. J Ekon Kesehat Indones [Internet]. 2016;2(1). Available from: https://doi.org/10.1002/stem.438

2. Maharani R, Budianto A. Pengaruh Beban Kerja terhadap Stress Kerja dan Kinerja Perawat Rawat Inap Dalam. J Manage. 2019;3(2).

3. Maryati W, Rahayuningrum IO, Sari NP. Dampak Beban Kerja Coder yang Tinggi terhadap Ketidakakuratan Kode Diagnosis. 2020;

4. Djalla A, Hafidza RN, Patintingan A. Faktorfaktor yang Mempengaruhi Profesionalisme Petugas Kesehatan di Puskesmas Baroko Kabupaten Enrekang. J Ilm Mns dan Kesehat. 2018;1(1).

5. Junaidi, Herawati H, Hidayatullah S. Pengaruh Pendidikan dan Pelatihan terhadap Kinerja Pegawai di Puskesmas Besuk Kecamatan Besuk Kabupaten Probolinggo. J Ecobuss. 2016;4(2):61-75.

6. Maisirata P. Penilaian efektivitas pelatihan bagi peningkatan prestasi kerja karyawan swasta di kota pontianak. J Manag Stud. 2019;4(1):7997.

7. Ambarita AJ, Ridho H. Pengaruh Mutasi terhadap Semangat Kerja Pegawai Negeri Sipil pada Kantor Pelayanan Pajak Pratama Kota
Pematang Siantar. 2015;8(2).

8. Awisna A. Pengaruh Mutasi terhadap Motivasi Kerja Pegawai pada Kantor Dinas Kesehatan Kabupaten Aceh Tamiang. 2017;

9. Syahyuni D. Hubungan Antara Kinerja Karyawan Dengan Promosi Jabatan Pada Unit Taman Marga Satwa Ragunan Dinas Kehutanan Provinsi DKI Jakarta. 2018;II(1).

10. Saharuddin, Soehardi. Pengaruh Kreativitas dan Promosi Jabatan Terhadap Peningkatan Produktivitas. J Ilm Manaj Ubhara. 2019;1-9.

11. Siregar T, Atmasari EZ. Faktor Determinan Pengembangan Jenjang Karir Perawat Di RSUD Pasar Minggu Jakarta Selatan. Junrla Ilm Kesehat Pencerah. 2020;09(40):10-8. 